\title{
Case report. Buccal mucosa graft voor UPJ-reconstructie na een niet-geslaagde robotgeassisteerde pyelumplastiek
}

\author{
Thijs Campschroer ${ }^{1}$ Olaf P. J. Vrooman² $\cdot$ Bin K. Kroon² $\cdot$ Michael R. van Balken²
}

Published online: 16 January 2019

(c) The Author(s) 2019

\section{Samenvatting}

Proximale ureterstricturen zijn een uitdaging voor de reconstructieve chirurgie. Transuretero-ureterostomie, ileuminterpositie en autotransplantatie zijn vaak genoemde mogelijkheden. Een wat minder bekend type reconstructie, de doorgaans succesvolle buccal mucosa graft (BMG) ureteroplastiek, is in kleine series in de literatuur beschreven. Wij beschrijven een casus waarin een BMG werd gebruikt voor herstel van een strictuur ter plaatse van de proximale ureter/uretero-pelviene junctie (UPJ) na iatrogeen ureterletsel en een niet-geslaagde robotgeassisteerde pyelumplastiek. Aan de hand van deze casus willen wij deze weinig bekende reconstructieve optie bij urologen onder de aandacht brengen.

Trefwoorden graft van wangslijmvlies $\cdot$ reconstructieve urologie $\cdot$ ureterstricturen $\cdot$ UPJ

\section{Case report. Use of buccal mucosa for UPJ reconstruction after failed robot-assisted pyeloplasty}

\begin{abstract}
Reconstructive surgery for proximal ureteral strictures is challenging. Transureteroureterostomy, ureteroileal interposition and autotransplantation are the methods most described. In literature, a somewhat less known type of reconstruction, the usually successful buccal mucosa graft (BMG) ureteroplasty is described in small case-series. We describe a case in which a BMG was used for the repair of a proximal ureteral/uteropelvine junction (UPJ) stricture following iatrogenic ureteral laceration and failed robot-assisted pyeloplasty. With this case-report we want to bring this less well known option of reconstruction to the attention of all urologists.
\end{abstract}

Keywords buccal mucosa graft $\cdot$ reconstructive urology $\cdot$ ureteral strictures $\cdot$ UPJ

\section{Introductie}

Behandeling van lange proximale ureterstricturen, waarbij excisie en aanleggen van een primaire anastomose niet haalbaar blijkt, behoeft vaak uitgebreide reconstructieve chirurgie. Hierbij worden opties zoals een transuretero-ureterostomie, interpositie met ileum en zelfs autotransplantatie in de literatuur beschreven [1-3]. Deze technieken geven respectievelijk potentiële afvloedproblemen van de niet-aangedane nier, verhoogde kans op infecties en elek-

drs. Thijs Campschroer

thijscampschroer@hotmail.com

1 afdeling Urologie, Radboudumc, Nijmegen, Nederland

2 afdeling Urologie, Rijnstate Ziekenhuis, Arnhem, Nederland trolytenstoornissen, en kans op nefrectomie. Binnen de reconstructieve urethrachirurgie worden vaak grafts (onder andere van wangslijmvlies; Eng. buccal mucosa) gebruikt. Sinds 1999 worden, hoewel nog sporadisch, deze grafttechnieken ook binnen de reconstructieve ureterchirurgie met fraaie uitkomsten toegepast, en worden deze ook in internationale caseseries beschreven [4-8]. Om deze weinig bekende reconstructieve optie in Nederland onder de aandacht te brengen, beschrijven wij een casus van een patiënte met een proximale ureterstrictuur na iatrogeen ureterletsel en een niet-geslaagde poging tot een robotgeassisteerde pyelumplastiek. 

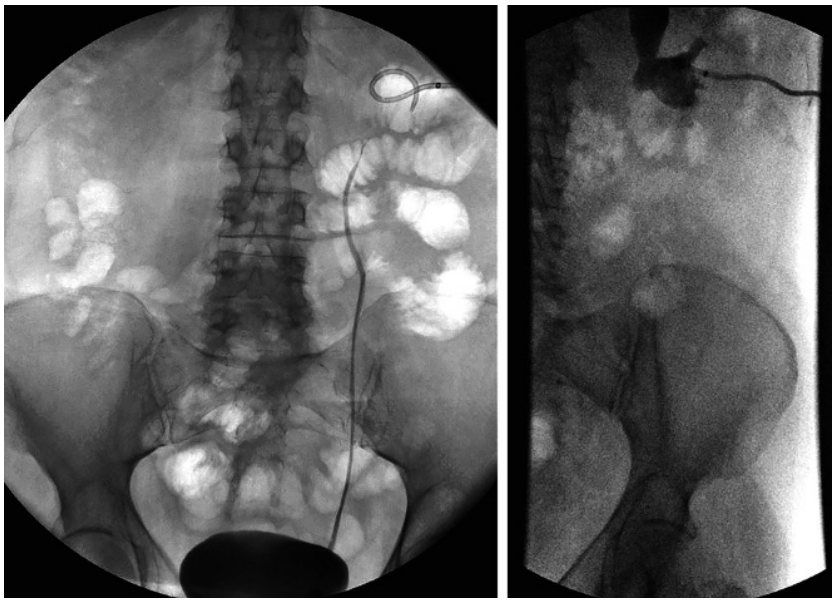

Figuur 1 Retrograde pyelografie van het iatrogene ureterletsel ten tijde van de ureterorenoscopie

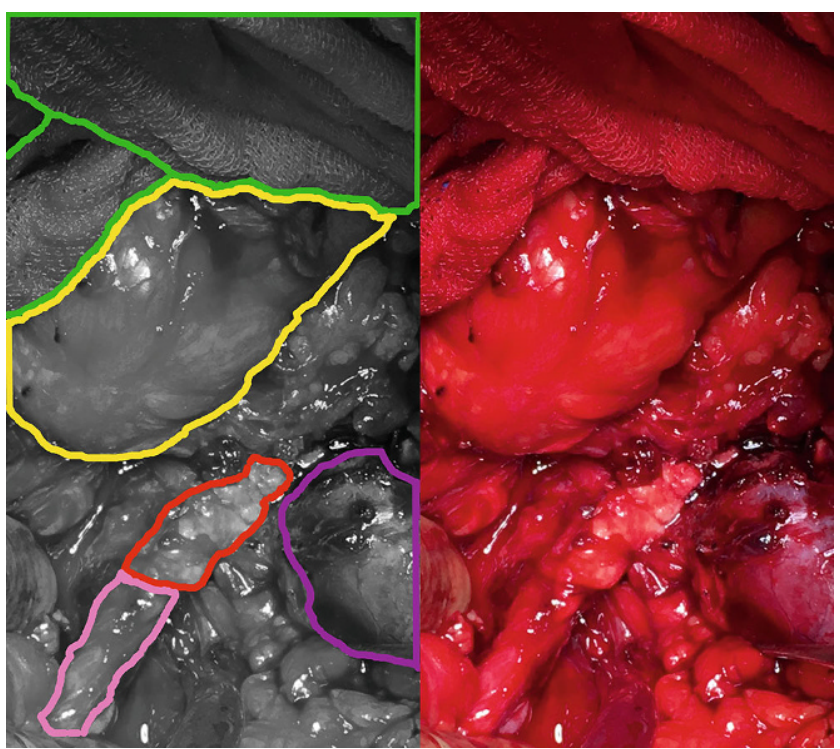

Figuur 2 Peroperatief beeld van de BMG-onlay op de proximale ureter. Paars nier, geel darm, groen buikgaas, rood graft, roze ureter

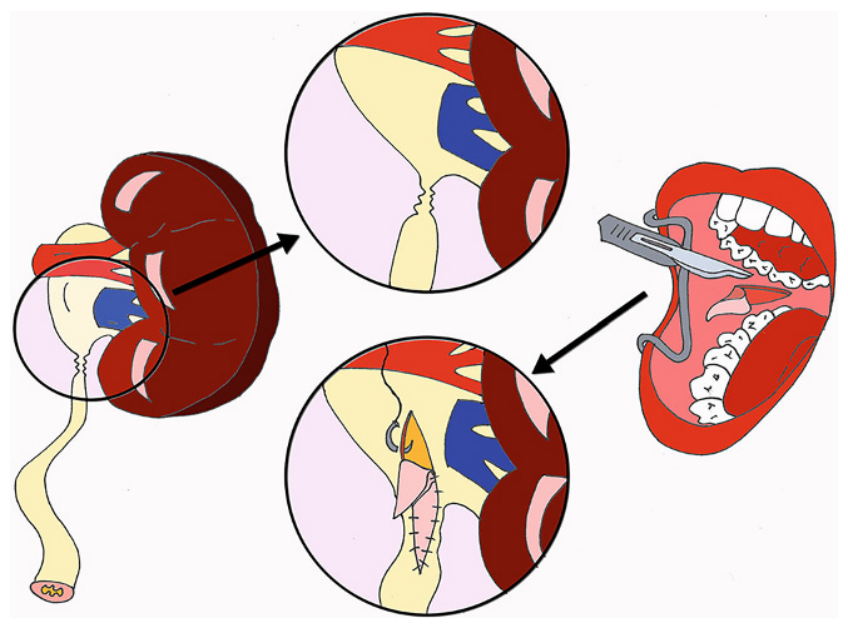

Figuur 3 Het stappenplan van de procedure

\section{Casus}

Een 55-jarige vrouw werd in het najaar van 2016 gezien op de polikliniek in verband met macroscopische hematurie. Haar voorgeschiedenis vermeldde het plaatsen en verwijderen van een maagband, een maagverkleining, (gastric bypass) en een correctie van een hernia cicatricalis met behulp van een mat ter plaatse van de rechterbuikhelft met inmiddels een recidief hernia, waarvoor expectatief beleid was afgesproken. CT-IVP (intraveneus pyelogram) toonde een steen in de onderpool van de linkernier van $10 \mathrm{~mm}$ doorsnee (HU: 590) als verklaring voor haar klachten. Er waren geen aanwijzingen voor anatomische afwijkingen van de linkernier of -ureter. Deze steen was op de buikoverzichtsfoto niet zichtbaar. Derhalve werd zij ingepland voor een flexibele ureterorenoscopie links. Peroperatief was het beeld van een relatieve stenose ter plaatse van de UPJ zichtbaar, waarbij een voerdraad deze goed kon passeren. De flexibele ureterorenoscoop wilde echter niet goed passeren en, hoewel de manipulatie zeer gering was, ontstond een partiële ruptuur van de ureterwand (fig. 1). Zonder problemen werd een JJ-katheter over de aanwezige voerdraad geplaatst, alsmede een transurethrale katheter, en de procedure werd beëindigd. Postoperatief beloop was ongecompliceerd en bij controle na vier weken toonde de CT-IVP een ureter en UPJ zonder contrastlekkage en geen perirenale vochtcollecties. De JJ-katheter werd verwijderd en een MAG3scan toonde nadien geen evidente afvloedbelemmering, met een functieverdeling $69: 31 \%$ ten nadele van rechts. Er werd een nieuwe ureterorenoscopie (URS) gepland, waarbij opnieuw een relatieve stenose werd gezien, die niet te passeren bleek.

$\mathrm{Na}$ de operatie werd met de patiënte besproken dat bij de endoscopie wel een UPJ-stenose was gezien, maar dat die volgens de MAG3-scan geen functionele afvloedbelemmering gaf. Om toch de pijnklachten (mogelijk van de steen of de relatieve afvloedbelemmering) te kunnen verhelpen, werd aan de patiënte voorgesteld om een robotgeassisteerde pyelumplastiek uit te voeren, waarbij dan, indien mogelijk, tijdens dezelfde procedure, steenextractie zou plaatsvinden. De operatie vond plaats twee maanden na de laatste URS. Peroperatief bleek de ureter tot proximaal te vervolgen, alwaar deze in een zeer fibrotisch gebied verdween, waarvan de anatomie niet goed herkenbaar was. Er vond een release van de ureter plaats tot aan het fibrotische gebied. $\mathrm{Na}$ minimale manipulatie ontstond reeds ureterletsel en een letsel ter plaatse van het pyelum: beide werden overhecht. Om verdere schade te voorkomen, werd een JJ-katheter geplaatst in de hoop dat de release van de ureter voldoende zou zijn om de pijnklachten te doen verdwijnen. Postoperatief ontwikkelde patiënte een urosepsis waarvoor antibiotische behandeling plaatsvond. De opties voor hernieuwde reconstructie werden met patiënte besproken. Ditmaal zou 
Hier staat een advertentie.

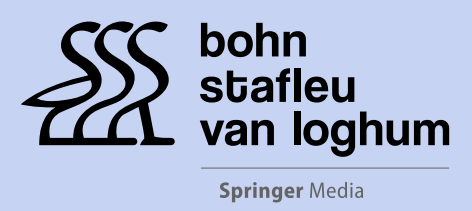

Houten 2019 
Hier staat een advertentie.

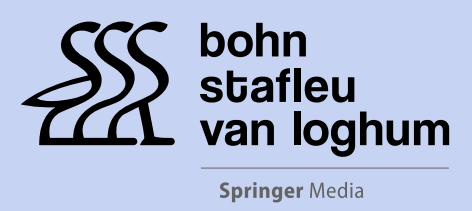

Houten 2019 
een open pyelumplastiek worden geprobeerd, waarbij - afhankelijk van de peroperatieve bevindingen - besloten zou worden welke reconstructie mogelijk was. De optie van een nefrectomie links werd, gezien het functionele aandeel van $69 \%$, alleen als laatste, meest ingrijpende mogelijkheid beschouwd. In de wachttijd tot de reconstructie werd de patiënte opgenomen in verband met koorts en toename van flankpijn links. De CT-scan toonde een geïnfecteerd urinoom naast het pyelum van circa $10 \mathrm{~cm}$ doorsnee. Hiervoor vond percutane drainage plaats. Vanwege persisterende urinelekkage, ondanks JJ, werd links ook een nefrostomiekatheter (NSK) geplaatst. Na drainage knapte patiënte vlot op en kon zij zonder drain, met antibiotica, met ontslag, met JJ-katheter en NSK op afloop.

Twee maanden na de laatste infectieuze episode vond de open reconstructie plaats. Via een mediane bovenbuikslaparotomie werd uitgebreide adhesiolyse verricht en het colon gemedialiseerd. Met enige moeite werd de linkerureter geïdentificeerd en naar craniaal vervolgd. Ter plaatse van het pyelum was sprake van een zeer fibrotische massa conform het beschreven beeld ten tijde van de robotgeassisteerde pyelumplastiek. Middels een kleine incisie in de ureter werd geprobeerd een ureterkatheter op te voeren naar het pyelum, maar deze kon de UPJ niet passeren. De vaatsteel werd geïdentificeerd om, indien nodig, deze af te kunnen klemmen. Met kleine stappen werd de ureter in de lengte opengeknipt richting pyelum. Bij deze stap ontstonden enkele scheurtjes in het nierparenchym die gemakkelijk bloedden. De vaatsteel moest tweemaal twee tot drie minuten worden afgeklemd en met enige moeite werd adequate hemostase verkregen. Vanwege deze bloedingen werd peroperatief besloten de steenextractie achterwege te laten. Op identieke manier - zoals gebruikelijk bij een urethraplastiek - werd een buccal mucosa graft (BMG) geoogst. $\mathrm{Na}$ plaatsing van een JJ-katheter werd het wangslijmvlies spanningsloos als onlay graft op de ureter-pyelumovergang gehecht met Vicryl 4-0 (fig. 2 en 3). Van het omentum werd een gesteelde flap gemaakt, die als een omentale wrap rondom de ureter werd gepositioneerd. Er werd een drain en een transurethrale katheter achtergelaten. De NSK werd nog in situ gelaten. Patiënte kon vijf dagen na de operatie in goede conditie met ontslag. Twee maanden na de operatie toonden antegrade studies een fraaie doorloop van contrast naar de blaas met de JJ-katheter in situ. De NSK werd hierop verwijderd. De JJ-katheter werd een maand later verwijderd onder antibioticaprofylaxe. Na vier maanden was de afvloed op de MAG3-scan wat vertraagd, zonder aanwijzingen voor obstructie (fig. 4). De pijnklachten in de linkerflank waren inmiddels verdwenen.

Voor de onderpoolsteen links zal vooralsnog een expectatief beleid worden gevoerd. Mocht zich in de toekomst een reden voor steenextractie voordoen, dan zal een percutane benadering - gezien bovenstaand ziektebeloop - logischerwijs de voorkeur hebben.

\section{Discussie}

BMG's worden in de reconstructieve urethrachirurgie veel gekozen vanwege de uitstekende weefselkarakteristieken (geen haargroei, rijk aan vaatvoorziening, gemakkelijk te verkrijgen, snelle ingroei in het omliggende weefsel, dik
Figuur 4 MAG3-scan van de postoperatieve situatie na drie maanden

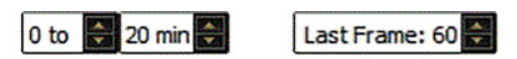

RENOGRAM

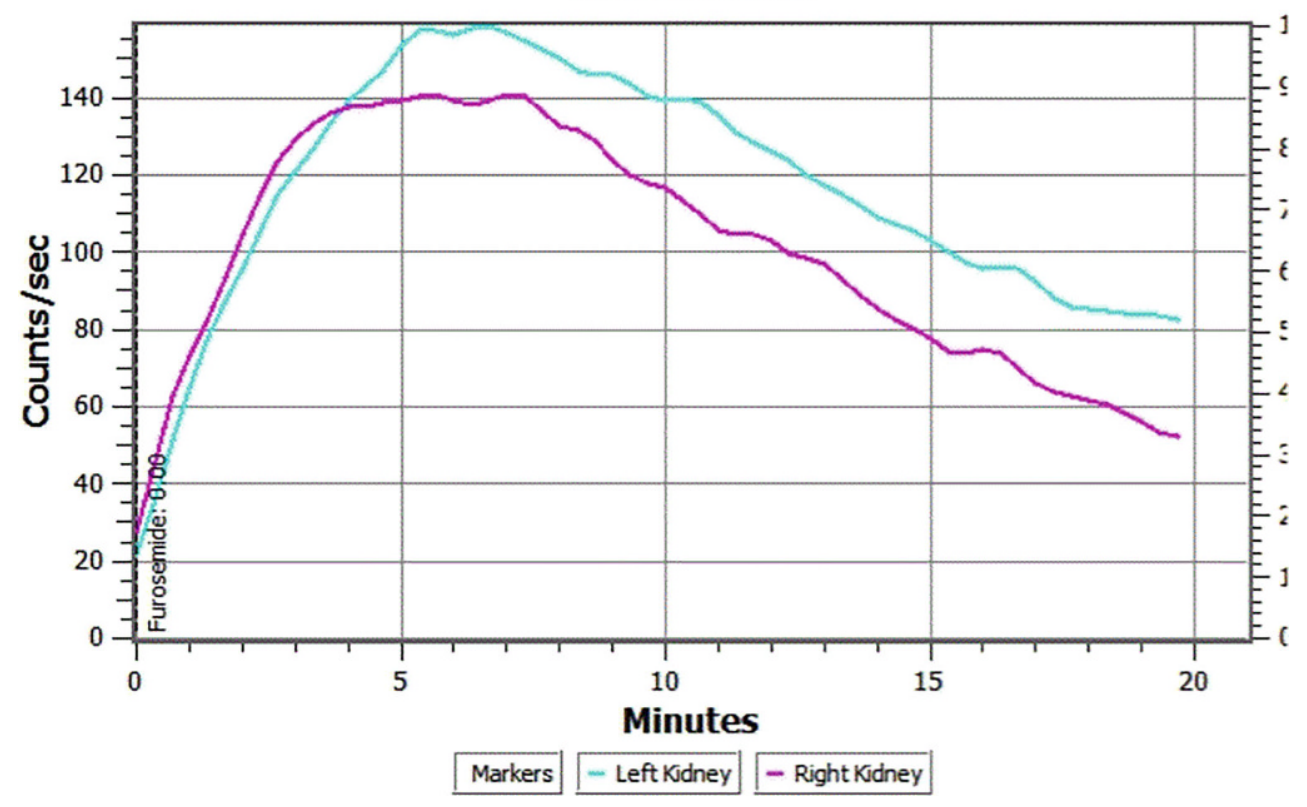


epitheel dat niet snel slinkt, laag infectierisico en geen kans op het ontstaan van huidaandoeningen, zoals lichen sclerosis). In de ureter is de BMG in 1984 voor het eerst in diermodellen met succes getest [9]. In 1999 werd deze toepassing voor het eerst ook beschreven bij menselijke ureteren [4]. Sindsdien zijn enkele caseseries beschreven waarin de BMG is toegepast bij lange proximale ureterstricturen. De laatste publicaties beschrijven het gebruik van de robotgeassisteerde techniek [10,11]. Wij hebben in onze casus bewust voor de open benadering gekozen, vanwege de complexiteit van de eerdere robotgeassisteerde procedure en de complicaties die daarna optraden (urinoom met abcedering, behandeld met percutane drainage). Ook wij hebben, net als in de literatuur wordt aanbevolen, een gesteelde omentale flap gebruikt om de BMG na reconstructie van de ureter nog extra te bekleden. Omentale flappen worden binnen andere specialismen vaker gebruikt ter ondersteuning van transplantaten, bijvoorbeeld als bodem voor split skin grafts in thoraxwanddefecten na radiotherapie [12]. Ideale kandidaten voor een BMG-ureterreconstructie zijn patiënten met een ureterstrictuur die te lang is voor directe anastomose, maar bij wie de rest van de ureter voldoende kwaliteit heeft om te kunnen volstaan met een onlay van BMG in combinatie met een gesteelde omentale flap. Mocht deze techniek niet slagen, dan kan altijd nog de stap naar ingrijpender methoden worden genomen.

\section{Conclusie}

Proximale ureterstricturen die te lang zijn voor resectie en primaire anastomose kunnen goed met behulp van een BMG-ureteroplastiek worden behandeld. Deze weinig bekende techniek laat in kleine caseseries fraaie uitkomsten zien en is een minder ingrijpende stap dan ileum-interpositie of autotransplantatie. De hier beschreven reconstructietechniek had in deze casus ook robotgeassisteerd kunnen worden uitgevoerd.

Open Access This article is distributed under the terms of the Creative Commons Attribution 4.0 International License (http:// creativecommons.org/licenses/by/4.0/), which permits unrestricted use, distribution, and reproduction in any medium, provided you give appropriate credit to the original author(s) and the source, provide a link to the Creative Commons license, and indicate if changes were made.

\section{Literatuur}

1. Watterson JD, Mahoney JE, Futter NG, Gaffield J. Iatrogenic ureteric injuries: approaches to etiology and management. Can J Surg. 1998;41(5):379-82.

2. Chung BI, Hamaway KJ, Zinman LN, Libertino JA. The use of bowel for ureteral replacement for complex ureteral reconstruction: longterm results. J Urol. 2006;175:179-83.

3. Eisenberg ML, Lee KL, Zumrutbas AE, Meng MV, Freise CE, Stoller ML. Long-term outcomes and late complications of laparoscopic nephrectomy with renal autotransplantation. J Urol. 2008;179:240-3.

4. Naude JH. Buccal mucosa grafts in the treatment of ureteric lesions. BJU Int. 1999;83:751.

5. Agrawal V, Dassi V, Andankar MG. Buccal mucosal graft onlay repair for a ureteric ischemic injury following a pyeloplasty. Indian J Urol. 2010;26:120-2.

6. Badawy AA, Abolyosr A, Saleem MD, Abuzeid AM. Buccal mucosa graft for ureteral stricture substitution: initial experience. Urology. 2010;76:971-5.

7. Sadhu S, Pandit K, Roy MK, Bajoria SK. Buccal mucosa ureteroplasty for the treatment of complex ureteric injury. Indian J Surg. 2011;73:71-2.

8. Kroepfl D, Loewen H, Klevecka V, Musch M. Treatment of long ureteric strictures with buccal mucosal grafts. BJU Int. 2010;105:1452-5.

9. Somerville JJ, Naude JH. Segmental ureteric replacement: an animal study using a free non-pedicled graft. Urol Res. 1984;12:115-9.

10. Lee Z, Waldorf BT, Cho EY, Liu JC, Metro MJ, Eun DD. Robotic ureteroplasty with buccal mucosa graft for the management of complex ureteral strictures. J Urol. 2017;198(6):1430-5.

11. Zhao LC, Weinberg AC, Lee Z, et al. Robotic ureteral reconstruction using buccal mucosa grafts: a multi-institutional experience. Eur Urol. 2018;73(3):419-26.

12. Domene CE, Volpe P, Onari P, et al. Omental flap obtained by laparoscopic surgery for reconstruction of the chest wall. Surg Laparosc Endosc. 1998;8(3):215-8.

drs. Thijs Campschroer aios urologie

drs. Olaf P.J. Vrooman uroloog

dr. Bin K. Kroon uroloog

dr. Michael R. van Balken uroloog 